TRANS · NÚM. I2 $\cdot 2008$

DOSSIER $\cdot 81-94$
El artículo presenta un proyecto de investigación acerca del papel de la traducción en la prensa independentista de Venezuela de 1808 a 1822. Da cuenta de un primer acercamiento a los seis periódicos más importantes de la época, después de plantear un marco teórico, metodológico, periodístico e histórico. Se estudian para cada uno de estos periódicos la línea editorial, los directores y demás características, y se ofrecen los primeros resultados de la extracción de información acerca del contexto general y de las traducciones publicadas en los periódicos.

PalabRAS Claves: Traducción, prensa, independencia, identidad, Venezuela.

\title{
La traducción como elem
creador de identidad en \\ la prensa independentista de Venezuela (I808-I822)
}

Georges L. Bastin

Universidad de Montreal

$\mathrm{M}^{\mathrm{a}}$ Gabriela Iturriza

Universidad de Montreal
This article presents a research project on the role played by translation in the Venezuelan press from 1808 to 1822 . After describing the theoretical, methodological, journalistic and historical framework, a first approach to the six most significant newspapers of the time is proposed. The study centers upon the editorial line, the directors and some other characteristics of each newspaper. Finally, the paper offers some preliminary results concerning the general context and describes some the translations published during that time.

KEYWORDS: Translation, press, independence, identity, Venezuela. 


\section{INTRODUCCIÓN}

La independencia de Venezuela, primer país de 82 Hispanoamérica en declarar su autonomía frente a la corona española el ig de abril de i8ro, fue el resultado de insurrecciones populares desde I749, de conspiraciones y de guerras sangrientas hasta I823. Estos movimientos y luchas encuentran su motivación en la condición colonial del país: esclavitud (de africanos e indígenas), bajo desarrollo agrícola e industrial y por lo tanto dependencia casi total de las importaciones, y la discriminación social. Estos movimientos se alimentaron, desde el principio del siglo xviII de las ideas emancipadoras provenientes de Europa y del norte del continente gracias a la traducción. En efecto el papel fundamental desempeñado por la traducción durante esta época en América hispana y en particular en Venezuela quedó demostrado gracias al estudio de las traducciones españolas de textos «fundacionales» como la Declaración de independencia de los EEUU, las dos Declaraciones de los Derechos del Hombre y del Ciudadano de la Revolución francesa y la Carta a los Españoles Americanos de Juan Pablo Viscardo y Guzmán, así como textos filosóficos norteamericanos (Thomas Paine y John Mculloch) y europeos (John Locke, Montesquieu, Rousseau y Voltaire, entre otros) y una canción revolucionaria francesa, $L a$ Carmagnole. Estos trabajos y varios otros referidos a la traducción en América Latina pueden consultarse libremente en el sitio web del Grupo de Investigación HISTAL.

Un factor de peso en estos movimientos independentistas fue la discriminación social hacia los criollos en la administración colonial. La elite criolla vivía una condición ambigua por el hecho de detentar un poder económico considerable así como una cuota de poder político significativa en el seno de los cabildos, sin embargo se veía en la imposibilidad de acceder a los cargos gubernamentales reservados a los peninsulares de quienes eran herederos directos por la sangre. Estos criollos, poderosos terratenientes y comerciantes así como a menudo intelectuales «ilustrados», fueron los verdaderos artífices de la independencia. La confusión de poderes en España a raíz de la invasión napoleónica y el desorden que ésta originó en América llevaron a los criollos a afirmar su identidad de «fundadores y legítimos dueños» de América frente a un poder imperial en plena debacle.

Si bien las ideas de la Ilustración desempeñaron un papel clave en la toma de conciencia por parte de los americanos de su condición colonial y de la necesidad de poner fin a ésta, el epicentro y verdadero propagador de las ideas independentistas fue la prensa de la época, la más «caliente» de la independencia (I808-1822). Editada, dirigida y redactada por políticos y letrados pertenecientes a la elite criolla, dicha prensa alcanzaba una audiencia significativa en ciudades y poblaciones del territorio así como en el extranjero. Como se reseña en la Gaceta de Caracas a inicios de I8II, en vísperas de la independencia: «Habiendose duplicado la Gazeta, y aumentandose su volumen tan considerablemente como lo ha visto el público; debe haberse escaseado por consequencia el tiempo y aumentandose el trabajo [...] a penas hay 24 horas para componerla, corregirla tres veces y tirar 500 ejemplares desde la 6 de la mañana del Miércoles hasta las 6 de la tarde del Jueves que parte el Correo de Puerto Cabello» (I5/or/ri; p. 3, col. 3).

La prensa es el registro de la historia de un país, el reflejo viviente tanto de los grandes acontecimientos como de hechos menores. Los grandes ideales y las noticias triviales alimentan las páginas de los periódicos para ser- 
vir los objetivos de sus editores. Estos tienen como primera preocupación suscitar la crítica del lector, además de informar, por lo que su propósito nunca es neutral. Cualquier periódico refleja las concepciones sociales, económicas, científicas o ideológicas de sus editores, redactores y mentores quienes más allá de su misión de informar persuaden para obtener la filiación de sus lectores. Si bien este es el caso de cualquier prensa en cualquier época, lo es aún más de la prensa colonial que constituye un ejemplo privilegiado de la voluntad de creación identitaria del lectorado por el hecho, entre otros, de la ambigüedad, fragilidad o inestabilidad de la identidad tanto de los hombres de prensa como del lectorado. En efecto, los primeros hombres ilustrados se consideraban «the same but not quite» (Bhabha 1994), es decir españoles por la sangre, pero a la vez americanos por el suelo del que habían sido exploradores y fundadores, y por lo tanto quienes tenían derecho a su propiedad y su gestión; en cuanto al segundo, se constituía de sujetos colonizados, letrados, comerciantes y artesanos, quienes reivindicaban el mundo que estaban edificando a la vez que pertenecían por subordinación al mundo de la metrópoli. Este es precisamente el caso de la prensa colonial en la época de la independencia de Venezuela (I808-I822), la cual resultó del vínculo entre las autoridades y los ideólogos de la gesta independentista, hombres públicos y ciudadanos letrados. Se trata de una prensa oficial al servicio de la nación en tanto ésta «evoca un todo y no hace referencia a los elementos constitutivos del conjunto» (Guerra, 200r: 336) o «subjetivación colectiva en que cualidades y cantidades se vuelven homogéneas y competentes para la sujeción del individuo al Estado» (Antelo, 1993:92 parafraseando a DeleuzeGuattari, I988) donde «las instituciones pautan a cada agente lo relevante para la definición de lo nacional» (ibid.).

Entre las fuentes de información y reflexión de los periodistas de la época figuran en buen lugar las noticias e ideas provenientes del extranjero, formuladas en otra lengua (artículos, correspondencia, testimonios, papeletas, manifiestos, etc.). Algunos textos eran incluso publicados en la prensa venezolana en dos o tres idiomas, por ejemplo, El Correo del Orinoco publicaba noticias en inglés y francés debido a que circulaba en las islas del Caribe y se difundía también, en forma muy restringida, en los Estados Unidos y Europa. La traducción constituía pues una actividad transcultural privilegiada que los redactores ponían al servicio de sus propósitos. El origen extranjero daba cierta credibilidad que los periódicos explotaban; por lo tanto la traducción se convirtió en la negociación de una identidad cultural que daba cuenta de la diferencia cultural, pero también en una herramienta de poder.

A pesar de ello la prensa colonial nunca ha sido objeto de un estudio traductológico, tal vez por la dificultad de abordar el corpus. En efecto la «traducción» en esta prensa no aparece a menudo bajo su forma convencional, es decir, stricto sensu. No siempre los redactores hacen mención del texto de origen y la mayoría de las veces conservan el anonimato. Además, la «traducción» en la prensa adopta generalmente un formato distinto al del texto fuente y frecuentemente sólo es una síntesis o una reformulación de éste. Los primeros resultados de este estudio indican que la proporción de traducciones en los artículos publicados por la prensa independentista es considerable en la mayoría de los periódicos de la época.

La hipótesis del presente estudio es entonces que el verdadero papel de la traducción en Venezuela, descrito e interpretado mediante un 
examen pormenorizado no sólo del contenido de las traducciones sino también de las estrategias traduccionales de los redactores-traductores de 84 la prensa de la época, es el de haber contribuido fuertemente a la consolidación del movimiento independentista, a la creación de una identidad nacional y a la constitución de una cultura propia en la región, a partir de imaginarios y representaciones provenientes de las metrópolis. El periodo estudiado es el que se corresponde exactamente con la duración de los periódicos mencionados, desde 1808 a 1822 . En cuanto al área geográfica, será Venezuela de I808 a I8I8 y, de I8I8 à I822, la Gran Colombia.

\section{LA PRENSA INDEPENDENTISTA VENEZOLANA}

De 1808 a I822, varios periódicos salen a la luz con una duración que va de algunos meses a varios años: La Gaceta de Caracas (de octubre de I808 a enero de I822), El Semanario de Caracas (de noviembre de I8Io a julio de I8II), El Patriota de Venezuela (de enero de I8II a enero de I8I2), El Mercurio Venezolano (de enero de I8II a mayo de I8II), El Publicista de Venezuela (de julio de I8II a noviembre de I8II), y El Correo del Orinoco (de junio de I8I8 a marzo de I822). A esta lista se puede añadir la revista El Lucero de la que sólo se llegó a publicar el prospecto y que iba a ser redactada por Andrés Bello y Francisco Isnardi; El Patriota Venezolano, también llamado Patriota Cumanés, del que sólo se conocen dos números extraordinarios; y finalemente el primer diario venezolano, el Boletín, impreso por Juan Baillío, en Valencia, con ıo números publicados del i2 al 22 de mayo de I8I2. También varios periódicos editados en I82I, especialmente en Colombia : El Correo del Zulia (del 28 de enero de I82I a septiembre de I822 con Talavera como director), la Gaceta de la ciudad de Bogotá (26 números de 8 páginas, del I3 de febrero de 1820 al I4 de febrero de I822), El Correo de Bogotá y/o la Gaceta de Colombia (de I82I a I83I, con Santander, Azuero y Soto como directores -este périódico fue el primero en anunciar la muerte de Napoleón-), la Gaceta de Santa Marta, El Patriota de Guyaquil (a partir del 2I de mayo de I82I con José María Roca como fundador y con un prospecto de Olmedo), entre otros ${ }^{\mathrm{I}}$.

Finalmente se ha descubierto (Leal, 2002) un periódico anterior a todos aquellos, publicado en Trinidad que pertenecía a la provincia de Venezuela hasta 1797. Se trata del Courier de la Trinité espagnole (del I3 de agosto de I789 al io de noviembre de I789) del que se imprimieron cinco números y sólo dos se conservan en el Archivo General de Indias (AGI). Este periódico venezolano, que no se puede calificar de «independentista», redactado a dos columnas, una en francés y la otra en español, es el primer periódico bilingüe, la primera publicación bilingüe y la primera traducción impresa en territorio venezolano ${ }^{2}$.

La gran mayoría de estos periódicos, generalmente semanarios, tienen en común el ser órganos de difusión de las ideas patrióticas e independentistas. Publican informaciones relativas a las batallas, a los progresos del proceso revolucionario, a las leyes y decretos gubernamentales y son una tribuna para el debate político. En su mayoría se publican en Caracas y todos son dirigidos por letrados comprometidos, por representantes de Sociedades

Algunos de estos periódicos han sido reeditados en versión facsimilar o son accesibles parcialmente por vía electrónica en el sitio del Centro de Investigaciones de la Comunicación (CIC) de la Universidad Católica Andrés Bello (UCAB) de Caracas: http://www.ucab.edu.ve/ucabnuevo/index.php?load=prensa_home.htm\&seccion $=263 \& \mathrm{P}$

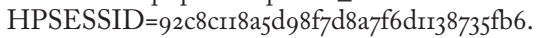

2 Trinidad, desde 1498 hasta I797, cuando la ganan los ingleses, es parte de Venezuela. 
Patrióticas o juntas y gobiernos revolucionarios y, además, cuentan entre sus redactores con nombres famosos como Francisco de Miranda, Andrés Bello, José Domingo Díaz, Francisco Isnardi, Miguel José Sanz, José Ignacio Abreu De Lima, Antonio Muñoz Tébar, Vicente Salias y Simón Bolívar.

Dos periódicos entre éstos se distinguen por su duración: La Gaceta de Caracas (698 números encontrados en I4 años) y El Correo del Orinoco (I28 números en 4 años). Son tal vez el mejor reflejo del proceso independentista.

\section{CONSIDERACIONES PARA EL PROCESO INDEPENDENTISTA}

El caos que acarreó la invasión napoleónica en España, la formación de una Junta Central Suprema (I808) y luego el Consejo de Regencia en Cádiz (I81o) suscitan en América numerosos cuestionamientos, principalemente el de determinar a quién corresponde la soberanía. Ahora, nuestro objetivo no consiste en clasificar los eventos o a los redactores de prensa según una óptica maniquea entre el carácter independentista o el interés de perpetuar un orden (principalmente económico y jurídico) establecido desde la metrópoli, sino apuntar la relectura, desde la mirada de la historiografía venezolana de la última década, de algunos eventos que también evidencian luchas aisladas, luchas por la autonomía de grupos fuera de las elites o conflictos por el estatus. Ejemplos de ello los presenta Leal (2002) sobre los pardos (considerados «hombres de «baja calidad» $\mathrm{y}$ «torpe linaje») o «clases bajas» (negros, indios, mestizos y mulatos), con las rebeliones contra los abusos de la Compañía Guipuzcoana: una de ellas,

\footnotetext{
3 En su trabajo Langue (2002) profundiza en los intereses y conflictos comerciales entre la Regencia española
}

por I732, en los Valles de Yaracuy dirigida por Andresote, antiguo esclavo, zambo y «jefe de una banda de contrabandistas que contó con el apoyo de negros esclavos e indios y otra, la del 85 canario (o blanco de orilla) Juan Francisco de León (1749-175I) revuelta casi colectiva, espontánea, sin propaganda [que] se había ganado la simpatía de la aristocracia criolla (Leal, 2002: 2I2). También las conspiraciones de los Comuneros de Mérida contra los impuestos establecidos por la Monarquía española en I780, las denuncias de los pardos gracias a la expedición de la Real Cédula de Gracias al Sacar en febrero de 1795 (Pino Iturrieta, 2000) y el alzamiento de negros dirigido por José Leonardo Chirinos en la Serranía de Coro en 1795 (Leal, 2002 y Langue, 2000).

En cuanto a las elites, desde la óptica de Langue (2000), encontramos la formación y declive de la Compañía Guipuzcoana y la creación del Real Consulado 4 en 1793 . Éste regulaba el comercio de la Provincia de Venezuela con España y servía para «evitar las discordias y para unir a los americanos y a los europeos, a los hacendados 5 y a los mercaderes en un mismo interés como era intensificar la agricultura y el comercio» (Leal, 2002: 222 y s.), lo que lo hacía un espacio de luchas y solidaridades entre grupos sociales de la aristocracia criolla

y los grupos de poder de la elite criolla en el declive de la Compañía Guipuzcoana y la creación del Real Consulado en 1793 .

4 Langue (2002) y Leal (2002) coinciden en que con la creación del Real Consulado se le otorga mayor poder a los criollos y «lo convirtieron en el rival directo del gobernador por lo que refiere a las decisiones de carácter político» (Langue: 128).

5 Según Langue (2002) el Real Consulado está ocupado por los grandes hacendados de ganado, café, cacao y mercaderes, grupos a los que pertenecen el Marqués del Toro y la familia Uztáriz. Para la autora, esta entidad en época independentista se identificó con los propósitos de la Junta Suprema y después con el gobierno republicano. 
cuyas redes de parentesco, pactismo y poder son complejas.

Lejos de establecer falsas causalidades 86 entre los acontecimientos en los que son determinantes las «redes de sociabilidad» (Langue, 2000), merece especial atención la conjuración de los mantuanos en 1808 , antesala a la conformación de la Junta Suprema Conservadora de los Derechos de Fernando VII (Junta Suprema de Caracas) el i9 de abril de I8ro (Quintero, 2002), entidad también integrada por criollos y que Langue (2000: I34) refiere con notable identidad de criterios y pareceres con respecto al Consulado y el Ayuntamiento, por lo que la adhesión al movimiento de emancipación no fue un hecho individual para los miembros del Consulado sino más bien el fruto de una decisión colectiva.

Son notorios como eventos independentistas previos a la creación de la Gaceta la conspiración de Gual y España en 1797 (que contó con los conspiradores de San Blas -Madrid, I796- entre ellos Juan Bautista Picornell) y los intentos de desembarco de Francisco de Miranda en Ocumare y luego en Coro (I806), a los que la elite criolla se opone. No obstante, sobre la traducción de Picornell, considerada como promotora del espíritu revolucionario de la década siguiente en Venezuela, Pino Iturrieta (2000: 43) advierte en el Discurso Preliminar de los Derechos de hombre y del ciudadano (I797-I798) «la reinvindicación del derecho de unos pocos» cuando el texto expresa «todos nuestros empleos $[\ldots]$ ¿no se confieren a extraños? [...] Nuestros fueros y privilegios, ¿se nos han guardado?». Esta prioridad que se le da a los peninsulares en la ocupación de altos cargos la evidencia el autor en las Observaciones preliminares del Acta de Independencia en Venezuela, sobre la que señala que si bien el espíritu emancipador no podía pretender la drástica ruptura con la cultura colonial, tampoco podían deshacerse de la preeminencia dada a "las criaturas mimadas de la comarca» (op.cit. p. 45).

Sobre la posición política que ocupan los sectores de la sociedad venezolana en el proceso independentista Quintero (sf) sintetiza:

Los mantuanos al momento de declarar la independencia no tenían como propósito irrumpir contra su propia hegemonía, por el contrario, aspiraban que la ruptura con España los consolidaría en el ejercicio directo del poder y les garantizaría el control de la sociedad, política, social y económicamente. Sin embargo, el mismo proceso, a pesar de ellos y sin que ocurriera un cambio en sus designios y aspiraciones, altera el orden de la sociedad, irrumpe contra los valores inamovibles de la tradición y promueve un proceso cuyo desenlace escapa al control de sus promotores [...] Igualmente, el rechazo inicial a la propuesta emancipadora por parte de los grupos pertenecientes a las capas inferiores de la sociedad, no implica la existencia de un proyecto alternativo cuyo objetivo fuese revolucionar el orden establecido, dar paso a una fórmula igualitaria en donde ellos tuviesen el control de la sociedad. (http://www.analitica.com/Bitblio/iquintero/ independencia.asp)

La primera expresión oficial de ruptura con España es la del Cabildo de Caracas que proclama su autonomía y soberanía y se constituye en Junta ${ }^{6}$ el ig de abril de i8ro (el de Buenos Aires y de Santiago de Chile algunos meses después). Habrá que esperar al 5 de julio del año siguiente (I8II) para la declaración de independencia y la instauración de la primera República, que dura sólo un año hasta julio de I8I2. Luego mediante la guerra de independencia se reconquista Caracas y se instala

6 Debe notarse que esta Junta se autodenomina «Junta Suprema Conservadora de los Derechos de Fernando VII». 
la segunda República que dura menos aún que la anterior (agosto de I8I3 hasta diciembre de I8I4). Finalmente en I82I, en la batalla de Carabobo, Bolívar vence definitivamente a las tropas españolas. La tercera República (I8I7) cede el paso a la Gran Colombia de I8I9 a I8zo.

\section{ANTECEDENTES EN LA PRENSA HISPANOAMERICANA}

La prensa se desarrolla en el periodo previo al nacimiento de las repúblicas hispanoamericanas. Entre los primeros periódicos y revistas, nacidos de la reunión de letrados, artistas o científicos encontramos la Gaceta de México y florilegio historial de las noticias de Nueva España (I722, por Juan Ignacio Castorena y Ursúa7), la Gaceta de Goathemala (I729-I73I), la Gaceta de Santa Fe de Bogotá (1735) de Lima (1743-1763) ${ }^{9}$, la Gazeta de la Habana (I764-1766) ${ }^{\mathrm{Io}}$, las Primicias de la Cultura de Quito (enero-marzo, I792) y el Telégrafo mercantil, rural, político, económico e histórico del Río de la Plata (I80I-1805) entre los más referidos por la histografía con cierta variación en las fechas.

Si la prensa venezolana sólo aparece en 1808, es porque la imprenta llega ese mismo año. Fecha muy tardía con relación a otros países

Según Leal (2002), aparece el I de enero de I722, de edición mensual sólo sale durante seis meses. Es en 1728 cuando se publica la Gaceta de México, de 1740-I742 el Mercurio de México y en 1768 el Diario literario de México.

8 Luego El Papel Periódico de la ciudad de Santa Fe de Bogotá (en r79i por Manuel Socorro Rodríguez), el Correo Curioso, Erudito, Económico y Mercántil de la Ciudad de Santa Fe de Bogotá (I80I), el Semanario del Nuevo Reino de Granada (en r808, por Francisco José de Caldas) y La Bagatela (I8II-I8I2, por Antonio Nariño).

9 Luego el Mercurio Peruano de la Historia, literatura y noticias públicas (I79I-I795).

ro Luego El Pensador en I764 y después el Papel Periódico de La Habana (1793-1804). como México (1540) y Perú (1584). Antes de 1808, Miranda había embarcado en el Leander una imprenta en la que edita entre otros su Proclama de 1806 y panfletos. Según Grases (1983: 87 $\mathrm{XIX}$ ), «es posible que algunos elementos de la imprenta de Gallagher en Trinidad hubiesen pertenecido al taller de Miranda en el Leander, que Gallagher adquirió del Precursor, a quien acabó de pagarle en enero de I808». Son las partes del taller de Gallagher en Trinidad y otras solicitadas en Granada, las que llegan a Caracas en 1808 por los empresarios Mateo Gallagher y James Lamb a petición del gobierno colonial. En esta imprenta se hizo en I8Io el primer libro publicado en Venezuela, el Calendario Manual y Guía Universal de Forestareos de Andrés Bello. Con esta imprenta nace igualmente la Gaceta de Caracas en 1808 como portavoz del gobierno español. La segunda fue traída por Simón Bolívar en I8II, a sus propias expensas, para servir los intereses de la primera República. La tercera (la de Juan Baillío, impresor oficial de la Revolución) se instala, siempre en I8II, en Valencia donde tiene su sede el gobierno republicano. La cuarta es introducida por Don Manuel Rivas en Cumaná en i8ı2. La quinta es nuevamente traída por Bolivar en Ocumare de la Costa, el 6 de julio de I8I6, con ocasión de la expedición de los Cayos. La sexta nuevamente es importada por Bolívar (por 2200 pesos) y se destina a la Provincia de Guayana. Quien la transporta de Trinidad a Angostura en I8I7 es Don José Miguel Istúriz. Esta es la imprenta de El Correo del Orinoco y su primer director es Andrés Roderich. Este último importa de Filadelfia la séptima y última imprenta «revolucionaria» en I82r. Destinada a Angostura, es enviada por el gobierno republicano a Cúcuta pero finalemente instalada en Maracaibo. 


\section{PROPUESTAS TEÓRICAS}

El estudio se sitúa claramente en el marco de 88 los estudios descriptivos e interculturales de la traducción tales como los concibió Toury (1995) y los partidarios de la Escuela de la Manipulación, principalemente Hermans (1985 y 1999), quienes insisten en la incidencia de las traducciones en la lengua y cultura de llegada. El enfoque es por lo tanto descriptivo, orientado a los textos de llegada. A través del estudio de las condiciones y estrategias que rigen la realización y publicación de las traducciones (aquí periodísticas) se pretende determinar su incidencia en la sociedad receptora.

Como lo afirma Lépinette: «... la traducción constituye primordialmente un proceso de transculturación o de mutación de las significaciones culturales de los textos traducidos que sólo puede ponerse en evidencia gracias a la historia de la traducción. Para nosotros, el conjunto de fenómenos de transformación macro y microtextuales que supone toda traducción no puede entenderse fuera de esta interpretación global de tipo transcultural que debe subsumir todos estos fenómenos» (2003: 69).

Este postulado nos ha llevado a adoptar dos conceptos básicos: el de hibridez tal como lo enuncian Bhabha (1994), Simon (I999) y García Canclini (I990) así como el de transculturación de Ortiz (1940) y Lépinette (op. cit.). Según Sherry Simon, la hibridez «se distingue del sincretismo, de la creolización y del mestizaje, conceptos que sugieren que a partir de la dinámica del encuentro cultural, nacieron nuevas identidades duraderas» (I999: 3I, nuestra traducción). Para Simon, la hibridez «no es una nueva síntesis, sino una culminación»; Simon comparte más bien la idea de Bhabha para quien la hibridez es «un espacio tercero», una zona de negociación, de disensión y de intercambio, el locus de una «cultura translacional que trasciende los esquemas de alteridad para expresar la deriva de las identidades contemporáneas» (Simon 1999: 39-40, nuestra traducción). En cuanto a la transculturación, Ortiz la define como el proceso de las transmutaciones culturales extremadamente complejas observables en Cuba en los campos económico, institucional, jurídico, ético, religioso, artístico, lingüístico, psicológico, sexual y otros de la vida (Ortiz 2002: 254).

En definitiva, el estudio interroga el papel de la traducción como discurso histórico «que contribuye a la toma de conciencia de los elementos subyacentes a una cultura propia, condicionando la definición de un Yo colectivo en términos de (a menudo en desprecio de) un Otro, del Otro» (St-Pierre I993: 6I, nuestra traducción).

La traducción, como mediación cultural, refleja en realidad una idiosincracia hispanoamericana que se inclina mayoritariamente del lado de la voluntad política y nacionalista de los actores de la independencia, pero también a veces del lado de los letrados y literatos clásicos fieles a la autoridad de los originales. La traducción se origina en un modo de ser, es decir, modo de pensar y modo de actuar, que la convierte en «una» cultura hispano-americana.

\section{PAUTAS METODOLÓGICAS}

E1 método descriptivo apunta a determinar tendencias de comportamiento traduccional, a generalizar acerca de las decisiones tomadas y a reconstruir las normas seguidas en la traducción, y finalmente proponer hipótesis verificables de su incidencia en el sistema políticocultural receptor.

Para ello, se empezó por situar los textos en el sistema cultural receptor analizando su aceptabi- 
lidad social, política y lingüística. Se seguirá con la comparación de los originales y traducciones para determinar las estrategias empleadas por los traductores y generalizar el concepto o el proyecto de traducción subyacente para finalmente determinar la incidencia de tal proyecto en el sistema político-cultural receptor.

Es de notar que el estudio de la prensa se sitúa en el marco de una historia de los «noacontecimientos» (non-événementielle) tal como la define Paul Veyne (I97I). Según Veyne: «El acontecimiento es diferencia. [...] Es acontecimiento todo aquello que no es por sí mismo» (I97I: I8, nuestra traducción). Veyne reprocha a los historiadores el hecho de que sólo ven la historia como un "claro en medio de un bosque inmenso» y luego se apropian ese bosque. En esta perspectiva la tarea del historiador, según Veyne, "consiste más bien en desbrozar las zonas fronterizas de este claro», consiste en no estudiar exclusivamente los «grandes acontecimientos reconocidos como tales desde siempre» (1971: 34, nuestra traducción). En pocas palabras, es preciso estudiar «la historicidad de la que no se tiene consciencia como tal». Las traducciones en la prensa revolucionaria son un buen ejemplo de acontecimientos aún no reconocidos. Hasta el momento existe, para este estudio en Venezuela, un solo trabajo acerca del Correo del Orinoco ${ }^{\mathrm{II}}$.

Concretamente, se plantean una serie de interrogantes. Primero en lo que concierne a la naturaleza de las traducciones: ¿Cuáles son sus fuentes? ¿Cuál es su contenido? ¿Son traducciones stricto sensu, «adaptaciones» o reescrituras? ¿De qué lengua y a qué lengua se efectuaron? Segundo en lo que concierne a los traductores:

II Richardson Bugliani, Leticia (1998). La traducción en el Correo del Orinoco. Tesis de Grado para optar al título de Licenciada en traducción. Caracas: Universidad Central de Venenzuela, Inédita.
¿Quiénes son? ¿Cuál fue su formación intelectual y su vivencia política/ideológica? ¿Qué estrategias de traducción adoptaron? Y tercero en lo que concierne a la finalidad de las traducciones: ¿Qué impacto se buscó a través de su publicación? ¿Qué impacto real tuvieron?

Dada la complejidad de las informaciones por recopilar, se diseñó un instrumento de recolección de datos (ficha) con los campos provisionales siguientes: . Fuente TO: periódico, libro o metalenguaje («trad. de»; LO; correspondencia; nota); 2. Autor TO: autor, redactor, entidad, anónimo; 3. Contenido: político, documento oficial, cultura, varios, etc.; 4. Fuente TT: periódico (prospecto, editores y directores, duración), fecha, $\mathrm{n}^{\circ}$, página; 5 . Traductor: mencionado, anónimo, inferido; 6. Varios: título, referencias a la traducción, etc.

\section{RESULTADOS PRELIMINARES}

Los resultados preliminares pertenecen a la fase arqueológica de extracción e identificación de los textos traducidos en los periódicos, de recopilación de informaciones relativas a los periódicos, a los TO, a los redactores/traductores. Aún no se han llevado a cabo los análisis comparativos.

Del Correo del Orinoco ${ }^{\mathrm{I2}}$ se han publicado 133 números de los cuales 5 extraordinarios, de I8I8 a I822. Sus editores fueron: Andrés Roderick (no I-9I), Tomás Branshaw (no 92-99) y W. Burrel Steward ( $\mathrm{n}^{\circ}$ I00-I28). Richardson (1998) ha repertoriado 262 traducciones de las cuales solo I5 stricto sensu. En cuanto a sus directores y redactores fueron Francisco Antonio Zea ( ${ }^{\circ}$ I-I2), Juan Germán Roscio (n ${ }^{\circ}$ I2-83), José Luis Ramos (no 83-II7) así como José Rafael Revenga

I2 Los datos referentes al Correo del Orinoco se extraen de Richardson Bugliani 1998. 
y Manuel Palacio Fajardo. Tuvo entre sus colaboradores a Simón Bolívar y Francisco de Paula Santander, y entre sus corresponsales a José 90 María Blanco White y Cristóbal Mendoza. Un solo traductor es debidamente nombrado, José Luis Ramos, la inmensa mayoría son anónimos. Se infiere con base en los estudios de Richardson (1998) que otros traductores fueron los mismos directores y redactores por sus habilidades lingüísticas comprobadas y por ser algunos de ellos traductores de otros textos ${ }^{\mathrm{r}}$. Los textos fuentes son, en primer lugar, textos oficiales como leyes, decretos, reglamentos y discursos; en segundo lugar partes de guerra, proclamas, correspondencia, etc. y, en tercer lugar, textos varios como anécdotas, curiosidades, poemas y anuncios de publicaciones. Ejemplo notorio es la publicación (en el $\mathrm{n}^{\circ}$ extraordinario del $25 \mathrm{de}$ julio de I82I) de la Proclama relativa a la victoria en la batalla de Carabobo en tres idiomas (español, inglés y francés). Las traducciones provienen esencialmente de periódicos extranjeros: estadounidenses (Evening Post y General Adviser de New York, Federal Gazette y The Telegraph de Baltimore), ingleses (Morning Chronicle, Evening Mail) y franceses (Le Moniteur) y del Caribe (Trinidad Gazette, Barbados Mercury y Gaceta de Curazao). Los redactores no temían introducir citas no traducidas como en el $n^{\circ} \mathrm{I}$, dentro de un informe de guerra del sur del país «Noticia del Río Negro», donde aparece una cita en francés: «Un frère est un ami donné par la Nature», de Gabriel-Marie Legouvé, extraída del acto III, escena 3 de La Mort d'Abel, tragedia escrita en I792. El prologuista de la primera edición facsimilar, Luis Correa (1939), refiriéndose al Discurso de Angostura pronunciado por Simón Bolívar y publicado en cuatro números

I3 Esta conclusión, por ahora, puede generalizarse a los demás periódicos estudiados.

consecutivos del Correo del Orinoco (ig[3], $2 \mathrm{O}[\mathrm{I}], 2 \mathrm{I}[\mathrm{I}]$ y $22[\mathrm{I}])$, subraya la influencia de la traducción: «... esta influencia [de Montesquieu, Rousseau y Chateaubriand], vertida en el crisol de la lengua de Castilla, es la que nos da fisonomía propia, sabor de cosa nuestra» (Correa, I939: XIII).

Del Mercurio Venezolano (enero a mayo de I8II) sólo tres números (enero, abril y mayo) han sido publicados. Se termina su edición para dar paso a la de El Publicista de Venezuela. Su director fue Francisco Isnardi, intelectual de origen italiano, discípulo de los enciclopedistas y de Rousseau, fue corredactor del Acta de la Independencia. Preveía Isnardi publicar también la revista nonata El Lucero con Andrés Bello en el estilo del Mercure de France. El Mercurio, cuyo prospecto es reseñado en la Gaceta de Caracas (08/02/18II), es el «periódico» mejor concebido de los años I8Io-I8ı2; en realidad fue como una revista bastante voluminosa (6o páginas en el $n^{\circ}$ I., 48 en el no II y 48 en el no III). Su contenido variado era bien equilibrado, la calidad de la redacción excelente y las secciones precisas se mantienen a lo largo de los tres números: Política nacional, Continente americano, Resumen político (noticias de Europa acerca de la amenaza que representa Napoleón) y Varios (literatura y bellas artes). En cada número se encuentran noticias y comentarios acerca de la situación en Europa que son traducciones anónimas. Anuncia varias traducciones que no llegaron a ser publicadas y en «Libros Nuevos» $\left(\mathrm{n}^{\circ}\right.$ 3) informa la reimpresión de la versión española de La logique ou les premiers éléments de l'art de penser del abate Condillac, una de las primeras traducciones impresas en Venezuela.

De El Publicista de Venezuela (julio a noviembre de I8II), salen veintidós números. E1 director es Francisco Isnardi, secretario del Congreso constituyente. Su Prospecto preveé 
la transcripción in extenso de los debates del Congreso; la publicación de declaraciones (el n ${ }^{\circ}$ 2 retranscribe el texto íntegro de la Declaración de Independencia), leyes, disposiciones oficiales; la de noticias de las Provincias; de artículos doctrinarios; de un resumen político de América y Europa; y de textos varios. Se han repertoriado dieciséis textos traducidos: un discurso extraído de la Aurora de Filadelfia ( ${ }^{\circ}{ }_{4}$ ); un artículo de Samuel Johnson (1709-1784), autor del Dictionnary of the English Language de 1755 ( $\left.{ }^{\circ}{ }^{5}\right)$; tres artículos de Le Moniteur (n 8, 9 y 10); y varios textos de William Cobbett (I763-I835) conocido bajo el seudónimo de Peter Porcupine, defensor de la Inglaterra rural contra los trastornos de la revolución industrial y periodista con ideas radicales en contra de los intereses económicos (n ${ }^{\circ}$ I2-15, I7, I9-22).

De El Patriota de Venezuela (enero de I8II a enero de I8I2), órgano de la Sociedad Patriótica, se publicaron siete números de los cuales dos se han perdido. Periódico bastante voluminoso, los $\mathrm{n}^{\mathrm{o}} 2$ y 3 cuentan respectivamente 54 y 64 páginas. Los directores eran Vicente Salias, médico, escritor y periodista revolucionario, autor de la letra del himno nacional de Venezuela y Antonio Muñoz Tébar, orador, congresista, secretario de Francisco de Miranda y miembro de la Sociedad Patriótica. Se identificaron tres traducciones: un texto de Francisco de Miranda de I795 escrito en francés ( $\mathrm{n}^{\circ}$ 2), un artículo del Barbados Mercury $\left(\mathrm{n}^{\circ} 6\right)$ y un artículo del Courier d'Angleterre ( $\mathrm{n}^{\circ}$ 6). Como en los otros periódicos los traductores son anónimos; sin embargo uno de sus directores, Vicente Salias, bachiller en filosofía y en medicina, era traductor, funcionario «traductor de lenguas» de la Capitanía General de Venezuela (Servicios de Hacienda) en los primeros años de siglo XIX.

La Gaceta de Caracas (octubre de I808 a enero de 1822) es un periódico en sus inicios realista, portavoz de la Capitanía General de Venezuela y al servicio de los intereses de la España invadida por Napoléon. La Gaceta se vuelve republicana durante la Primera, Segunda y Tercera República, pero retoma su orientación realista cada vez que los españoles recuperan el poder. Se publicaron trescientos números en catorce años. Su primera divisa en la edición del 27 de abril de i8ro fue «Salus populi suprema lex esto» [La salud del pueblo es la ley suprema] y luego, en el segundo periodo patriotico, cuarto número de I8I3 (I6/og/ı3) cambia el epígrafe latino por el francés «L'injustice á la fin produit l'Independance» [La injusticia al final produce la Independencia].

Sus directores fueron varios. El más conocido, Andrés Bello, de octubre de I808 a septiembre de I8ro cuando sale en misión diplomática a Londres. Humanista, legislador, poeta, crítico, educador y filólogo, "primer humanista del continente», Andrés Bello ${ }^{\mathrm{I} 4}$ fue uno de los grandes traductores de América. Juan Germán Roscio, doctor en derecho canónico y derecho civil, principal redactor del Acta de independencia y corredactor de la Constitución de Venezuela. Francisco Xavier Uztáriz (julio de I8II-enero de I8I2), jurista, político, legislador y humanista, dirigente del movimiento revolucionario de abril de I8ro. Su familia era famosa por las tertulias de su casa «a la que asistía lo más notable de su generación» (Fundación Polar, I998). Vicente Salias (18I3-I8I4) (ver El Patriota) y José Domingo Díaz, médico, cronista, historiador y periodista (ver Semanario). En los periodos patrióticos se insertan extensas columnas de diarios extranjeros con noticias relativas a Europa, en muchos casos sobre movimientos militares o comerciales que desfavorecen a la

I4 Ver su biobibliografía en http://www.histal.umontreal.ca/espanol/versionsp.htm 
Corona. Se silencia de esta forma la voz de la Suprema Junta Central o cualquier papel que diera cuenta sobre el poderío de ésta en la Provincia venezolana ${ }^{\mathrm{I} 5}$.

Los fines de la Gaceta varían según los representantes gubernamentales y con ellos los redactores asignados al periódico. Durante el primer periodo patriótico, iniciado con la conformación de la Junta Suprema de Caracas en abril de i8ro, la Gaceta se hallaba, desde octubre de $1808^{16}$ bajo la dirección-redacción de Andrés Bello, quien la deja en junio de I8ro cuando parte asignado a Londres. Quedan en la dirección Francisco Isnardi con estrecha relación con Juan Germán Roscio hasta junio de I8II, cuando la toma Francisco Xavier Uztáriz y en octubre del mismo año pasa de nuevo a la dirección de Isnardi. Todos letrados, en su estricto sentido (filósofos, juristas y médicos) que, lo más seguro, ejecutan en sus direcciones la traducción de un grueso corpus de papeles, cartas, manifiestos, proclamas, discursos, proyectos y demás noticias de otras naciones. En este sentido importa destacar las construcciones de sentidos en torno a la identidad del hombre americano y la relación entre éstos, que no es fortuita, pues comparten espacios de sociabilización y comportan desde sus disciplinas un cuerpo jurídico y social.

Una primera aproximación a la labor de estos traductores nos permite establecer unos primeros vínculos. Andrés Bello, humanista,

I5 Salvo lo estudiado por Iturriza (2008, ver la presente edición), por lo extenso del corpus y lo incipiente del proyecto, aun no se han repertoriado las traducciones.

${ }^{16}$ Este periodo cuenta con el primer colaborador de la Gaceta, amigo de Bello, el Presbítero Mariano de Talavera y Garcés, quien firma bajo seudónimo «Un eclesiástico del Obispado de Mérida de Maracaibo». Ratto Ciarlo (197I) considera que Pedro Grases podría atribuirle la traducción del trabajo A los habitantes de la América Española, de «expresiones americanistas», publicado en al Gaceta del 25 de noviembre de 1808 . legislador, filósofo, educador y filólogo posee desde niño pasión por las lecturas del Siglo de Oro. Durante sus estudios da clases a Simón Bolívar y se manifiesta como literato en las tertulias de la familia Uztáriz. En junio de r8io es enviado junto con López Méndez y Bolívar en misión diplomática a Londres, donde conoce a Francisco de Miranda, quien le concede el acceso a su biblioteca en Grafton Street. Juan Germán Roscio es abogado y doctor en derecho canónico y en 1808 se desempeña como fiscal interino de la Real Audiencia y en abril de i81o en el Cabildo se incorpora como «diputado del pueblo», además de ocupar en la Junta Suprema la secretaría de Relaciones Exteriores, de la que Bello era oficial primero. Durante la dirección de la Gaceta en i8ro-I8II traduce, según Ratto Ciarlo (197I), las Reflexiones de William Burke. Recibe de Bello el dictado de «padre, maestro y defensor de la naciente libertad» (Fundación Polar, 1998).

Francisco Xavier Uztáriz, legislador, jurista y humanista, se destaca por sus conocimientos en doctrinas políticas «más avanzadas para su tiempo». Protege a artistas y literatos y convoca a un proyecto de biblioteca, según Langue (2000), de la que ofrece encargarse del acopio además de algunas traducciones, como el Diccionario de Agricultura del abate Rozier; integra la Junta de gobierno del i9 de abril y dos años después es parte del Poder Ejecutivo Plural con Roscio, entre otros. Según Leal (2002:108 y s.) muchas de las obras de los 2.300 escritores leídos en Venezuela desde el siglo xvir hasta $\mathrm{I} 767^{\mathrm{I}}$, se hallaban principalmente en casa de

17 Se refiere a Libros y bibliotecas en Venezuela colonial (1633-1767) (1978). Caracas: Academia Nacional de la Historia. Entre las lecturas se hallan escritores latinos clásicos, representantes del Siglo de Oro español, juristas, canonistas, libros de cocina, moda, juegos de azar «libros [escritos] en latín, inglés, francés, italiano y portugués, obras heréticas 
los Uztáriz e Isnardi. Francisco Isnardi, comerciante y poseedor de conocimientos de física, astronomía y medicina, en 1807 da clases de latín a los criollos y en 1809 conoce a Andrés Bello con quien intenta publicar la revista El Lucero; era además redactor del Mercurio venezolano en enero de i8ro y redactor de la Gaceta entre finales de ese año y principios del siguiente $^{\mathrm{I} 8}$.

De El Semanario de Caracas (4 de noviembre de I8Io al 2I de julio de I8II), periódico realista publicado por José Domingo Díaz y Miguel José Sanz, sus directores, se publicaron treinta números. Resulta extraña la colaboración entre dos personajes tan opuestos ideológicamente. Miguel José Sanz es jurista, político y periodista. Simpatiza con la conspiración de Gual y España y manifiesta su agrado por las expediciones de Miranda. Es amigo de éste. En I8II es Secretario del Congreso y ocupa el cargo de Secretaría de Estado, Guerra y Marina. Más tarde Bolívar le encarga la revisión del Proyecto de Constitución que realiza Uztáriz, se le pide además opinión sobre establecer un gobierno provisorio en Venezuela. Por su parte José Domingo Díaz es licenciado en filosofía (I788), médico cirujano (I794) y doctorado (I795). Tiene larga y conocida trayectoria como médico, pero también como traductor ya que en 1803 traduce un trabajo de Benjamin Pinsh sobre la calentura biliosa y las obras de Benjamin Rush sobre la fiebre amarilla en seis volúmenes (Fundación Polar, I998). Díaz hizo la guerra a muerte a los patriotas a punta de pluma y es recordado por sus invectivas y sus calumnias a la Revolución a partir de 1815 en la Gaceta de Caracas.

y sediciosas, clásicos, latinos, griegos y castellanos» (Leal, 2002: I09)

I8 Las referencias sobre los autores fueron obtenidas del Diccionario de Historia de la Fundación Polar (1998).

\section{A MANERA DE CONCLUSIÓN}

En este trabajo sólo se ha dado cuenta de un proyecto de investigación y de sus primeros resultados los cuales revelan el peso y la importancia de la traducción en la prensa independentista venezolana. Si bien no constituye evidentemente la mayor parte del contenido de los artículos, su proporción es significativa. Resalta, por otra parte, el lugar preponderante que ocupan los traductores entre los redactores de los distintos periódicos estudiados.

RECIBIDO EN ENERO 2008 ACEPTADO EN FEBRERO 2008

\section{REFERENCIAS}

Academia Nacional de la Historia (1983). La Gaceta de Caracas. Caracas: Biblioteca de la Academia Nacional de la Historia.

Academia Nacional de la Historia (1960). Mercurio venezolano-I8II-. Caracas: Academia Nacional de la Historia.

Academia Nacional de la Historia (1959). El Publicista de Venezuela. Caracas: Academia Nacional de la Historia.

Academia Nacional de la Historia (1959). Semanario de Caracas. Caracas: Academia Nacional de la Historia.

Antelo, R. (1993). «Estado sin nación, nación sin sociedad, sociedad sin lenguaje». En Beatriz González Stephan, Xavier Lasarte, Graciela Montaldo y Maria Julia Daroqui. Esplendores y miserias del siglo XIX. Caracas: Monte Avila editores/Equinoccio, pp. 9I-Io2.

Bastin, G. L. (1996). «Bases para una historia de la traducción en Venezuela». Livius, 8, pp. 9-25.

Bastin, G. L. (1997). «Latin American Tradition». En Baker, M. (Dir.). Routledge Encyclopedia of Translation Studies. London: Routledge, pp. 505-512.

Bastin, G. L. (2003). «Por una historia de la traducción en Hispanoamérica». IKALA, 8 (I4): pp. 193-217.

Ciarlo Ratto, J. (I97I). Libertad de prensa en Venezuela. 
Caracas: Biblioteca de la Academia Nacional de la Historia.

Correa, Luis (I939). Correo del Orinoco, Corporación Venezolana de Guayana, Prólogo de la $\mathrm{I}^{\mathrm{ra}}$ ed. facsimilar.

Fundación Polar (1998). Diccionario de Historia de Venezuela. Caracas: Fundación Polar.

García Canclini, N. (1990). Culturas hibridas: Estrategias para entrar y salir de la modernidad. México: Grijalbo.

Grases, P. (I983). «Estudio preliminar». En La Gaceta de Caracas. Caracas: Biblioteca de la Academia Nacional de la Historia.

Grases, P. (198I). Preindependencia y emancipación (Protagonistas y testimonios) (Vol. 3). Caracas: Editorial Seix Barral.

Grases, P. (I98I). «Traducciones de interés políticocultural en la época de la Independencia de Venezuela». En Instituciones y nombres del siglo XIX, (Vol. 6,). Caracas: Editorial Seix Barral. pp. I37-I4O.

Grases, P. (195I). Materiales para la historia del periodismo en Venezuela durante el siglo XIX. Caracas: UCV, Ediciones de la Escuela de Periodismo.

Guerra, F.X. (200I). Modernidad e independencias. Ensayos sobres las revoluciones hispánicas. México: Fondo de Cultura Económica.

Hermans, Th. (I985) (ed.). The Manipulation of Literature. London: Croom Helm.
Hermans, Th. (1999). Translation in Systems. Manchester: St Jerome.

Langue, F. (2000). Aristócratas, honor y subversión en la Venezuela del siglo XVIII. Caracas: Biblioteca de la Academia Nacional de la Historia.

Leal, I. (2002). El primer periódico de Venezuela y el panorama de la cultura en el siglo XVIII. Caracas: Academia Nacional de la Historia.

Lépinette, B. (1997). «La historia de la traducción - Metodología. Apuntes bibliográficos». LynX Documentos de trabajo, I4.

Lépinette, B., et Melero Bellido, A. (2003). Historia de la traducción (Siglos XVI-XIX). Valencia: Universidad de Valencia. Servicio de publicaciones.

Moreno Sardà, A. (1998). La mirada informativa. Barcelona: Bosch Casa editorial.

Ortiz, F. (2002 [1940]). Contrapunteo cubano del tabaco y del azúcar. Madrid: Cátedra.

Richardson Bugliani, L. (1998). La traducción en el Correo del Orinoco (I8I8-I822) (Tesis de licenciatura). Caracas: Universidad Central de Venezuela.

St-Pierre, P. (1993). "Translation as a discourse of history». TTR, 6 (I), pp. 6r-82.

Toury, G. (1995) Descriptive Translation Studies - And Beyond. Amsterdam/Philadelphia: John Benjamins.

Veyne, P. (I97I). Comment on écrit l'bistoire : Essai d'épistémologie. París: Seuil. 